Article

\title{
Differential Diagnosis of Preeclampsia Based on Urine Peptidome Features Revealed by High Resolution Mass Spectrometry
}

\author{
Alexey S. Kononikhin ${ }^{1,2, *}$, Natalia V. Zakharova ${ }^{3}$, Viktoria A. Sergeeva ${ }^{3,4}$, Maria I. Indeykina ${ }^{3}$, \\ Natalia L. Starodubtseva 2,5,*, Anna E. Bugrova 2,3, Kamila T. Muminova ${ }^{2}$, \\ Zulfia S. Khodzhaeva ${ }^{2}$, Igor A. Popov ${ }^{2,5}$, Wenguang Shao ${ }^{6}$, Patrik Pedrioli ${ }^{6}$, \\ Roman G. Shmakov ${ }^{2}$, Vladimir E. Frankevich ${ }^{2}$, Gennady T. Sukhikh ${ }^{2}$ and Evgeny N. Nikolaev ${ }^{1}$ \\ 1 Skolkovo Institute of Science and Technology, 143026 Moscow, Russia; E.Nikolaev@skoltech.ru \\ 2 V.I. Kulakov National Medical Research Center for Obstetrics, Gynecology and Perinatology, \\ Ministry of Healthcare of the Russian Federation, 117198 Moscow, Russia; \\ anna.bugrova@gmail.com (A.E.B.); k_muminova@oparina4.ru (K.T.M.); z_khodzhaeva@oparina4.ru (Z.S.K.); \\ popov.ia@phystech.edu (I.A.P.); r_shmakov@oparina4.ru (R.G.S.); v_frankevich@oparina4.ru (V.E.F.); \\ g_sukhikh@oparina4.ru (G.T.S.) \\ 3 Emanuel Institute for Biochemical Physics, Russian Academy of Sciences, 119334 Moscow, Russia; \\ nvzakharova@ya.ru (N.V.Z.); viktoriya.shirokova@phystech.edu (V.A.S.); mariind@yandex.ru (M.I.I.) \\ 4 V. L. Talrose Institute for Energy Problems of Chemical Physics, N. N. Semenov Federal Center of Chemical \\ Physics, Russian Academy of Sciences, 119334 Moscow, Russia \\ 5 Moscow Institute of Physics and Technology, 141701 Moscow, Russia \\ 6 Institute of Molecular Systems Biology, ETH Zurich, 8092 Zurich, Switzerland; \\ wenguang.shao@imsb.biol.ethz.ch (W.S.); pedrioli@imsb.biol.ethz.ch (P.P.) \\ * Correspondence: A.Kononikhin@skoltech.ru (A.S.K.); n_starodubtseva@oparina4.ru (N.L.S.)
}

Received: 19 October 2020; Accepted: 1 December 2020; Published: 3 December 2020

check for updates

\begin{abstract}
Preeclampsia (PE) is a severe pregnancy complication, which may be considered as a systemic response in the second half of pregnancy to physiological failures in the first trimester, and can lead to very serious consequences for the health of the mother and fetus. Since PE is often associated with proteinuria, urine proteomic assays may represent a powerful tool for timely diagnostics and appropriate management. High resolution mass spectrometry was applied for peptidome analysis of 127 urine samples of pregnant women with various hypertensive complications: normotensive controls $(n=17)$, chronic hypertension $(n=16)$, gestational hypertension $(n=15)$, mild PE $(n=25)$, severe PE $(n=25)$, and 29 patients with complicated diagnoses. Analysis revealed 3869 peptides, which mostly belong to 116 groups with overlapping sequences. A panel of 22 marker peptide groups reliably differentiating PE was created by multivariate statistics, and included 15 collagen groups (from COL1A1, COL3A1, COL2A1, COL4A4, COL5A1, and COL8A1), and single loci from alpha-1-antitrypsin, fibrinogen, membrane-associated progesterone receptor component 1 , insulin, EMI domain-containing protein 1, lysine-specific demethylase 6B, and alpha-2-HS-glycoprotein each. ROC analysis of the created model resulted in $88 \%$ sensitivity, $96.8 \%$ specificity, and receiver operating characteristic curve $(\mathrm{AUC})=0.947$. Obtained results confirm the high diagnostic potential of urinary peptidome profiling for pregnancy hypertensive disorders diagnostics.
\end{abstract}

Keywords: urine peptidomics; preeclampsia; hypertension; proteomics; mass-spectrometry

\section{Introduction}

Preeclampsia (PE) is the most severe hypertensive pathology complicating $2-8 \%$ of pregnancies and is associated with increased risk of miscarriage, premature birth, disability in the newborns, 
and development of severe cardiovascular pathologies in women after pregnancy, as well as neonatal and maternal deaths [1-4]. Unlike other hypertensive pregnancy complications (chronic or gestational hypertension), PE occurs after the 20th week of pregnancy and is often associated with proteinuria and other signs of multiple organ dysfunction [5-10]. Timely and appropriate treatment is of particular significance to avoid the fateful outcomes. The identification of women at high risk before pregnancy or at least until the 13th week of gestation is extremely important for choosing an adequate management as abnormal placentation leads to more severe forms of the pathology and its early onset [11]. However, late onset PE ( $\geq 34$ weeks' gestation) may occur due to other intrinsic pathologies that may be triggered by pregnancy and are also related with abnormal uteroplacental and vascular remodeling, as well as with redistribution of blood flow, which is laid in the first trimester of pregnancy [12-15].

Several physiological pathways related to genetic, epigenetic, and environmental factors may be involved in PE [16]. Main risk factors include primipregnancy, long interval between pregnancies, advanced maternal age, pre-pregnancy obesity, diabetes, hypertension, antiphospholipid syndrome, ethnic background, and a previous and/or family history of PE [11,17-19]. The etiology of PE essentially relates to hypoxia resulting from abnormal trophoblast invasion and vascular and uterine remodeling. Predisposing genetic factors relate to polymorphisms in a number of proteins/genes essential for regulation of blood coagulation, vascular endothelial function, blood pressure, inflammation, and immunity, which are also essential in other systemic pathologies not associated with pregnancy, such as hypertension, vascular disease, thrombophilia, and systemic inflammation [19-24]. The dysregulation in expression of SERPIN proteins A3, A5, A8, B2, E1, E2, and G1 shown earlier may reflect some compensatory mechanisms in PE-placentas [16]. Thus, the maternal PE syndrome that appears in the second half of pregnancy can be considered as a systemic response to systemic failures in the first trimester, which can occur under various scenarios, depending on different combinations of numerous genetic and non-genetic factors, and may not depend only on a few of them.

Since the real causes of PE are laid long before its manifestation, there is an opportunity for timely diagnostics and appropriate management to improve maternal and perinatal outcomes. However, reliable screening tests for clinical application have not yet been developed. Among protein markers, abundant expression of metalloproteinases MMP-2 and MMP-9 (gelatinases A and B) in extravillous trophoblasts is highly related to extracellular matrix (ECM) degradation [25-27]. Levels of MMP-2 and its inhibitor TIMP-1 were shown to be significantly increased in PE [28,29]. A decreased circulation level of placental growth factor (PLGF) may predict the development of PE in the following 2 weeks [30,31]. Soluble fms-like tyrosine kinase-1 (sFlt-1) can block vascular endothelial growth factor (VEGF) and PLGF via their binding. Its increased level (or increased sFlt-1/PLGF ratio) may precede PE from the second trimester onwards [31-33]. The increased degree of circulating anti-angiogenic soluble endoglin (sEng) strongly correlates with PE severity [34,35]. Decreased levels of placental protein-13 and pregnancy-associated protein A in the first trimester as well as increased levels of pro-inflammatory cytokines and hypoxia induced factor $1 \alpha$ may also suggest PE; however, these features are less specific [36-40].

Urine seems to be the most convenient subject for research due to its relative stability and non-invasive collection. Since PE is often associated with renal pathologies and proteinuria, urine proteomic analysis may provide valuable information, for example it may distinguish PE from other hypertensive pregnancy complications, and may estimate the degree of disease severity, which is essential for further management. Mass spectrometry (MS)-based approaches proved to be the most effective in previous urine peptidome/proteome studies and provided most of the current information [41-47]. Currently, the proposed urine PE markers include reduced levels of PIGF, prostaglandin-H2 D-isomerase, and perlecan [41,48], as well as increased levels of specific fragments of $\alpha-1$-antitrypsin (SERPINA1), albumin, fibrinogen alpha chain, collagen alpha chain, uromodulin [41-45], and of some unidentified proteins [46,47]. Using high-performance liquid chromatography with tandem mass spectrometry (HPLC-MS/MS), we found 35 specific urine peptides originating from SERPINA1, uromodulin, and collagen alpha-1 chains (I and III), which reliably distinguished a 
particular PE group (10—mild PE; 10—severe PE) from normal controls [45]. However, the results of various studies are not consistent enough, and none of the particular markers described to date show sufficient sensitivity. We believe that creation of a differentiating peptide marker panel can essentially improve PE diagnostics, and remains of particular importance as a basis for the further development of accessible clinical methods.

Here, based on the analysis of 127 urine samples of pregnant women (including normotesive controls, chronic hypertension $(\mathrm{CH})$, gestational hypertension $(\mathrm{GH})$, moderate $\mathrm{PE}(\mathrm{mPE})$, and severe $\mathrm{PE}(\mathrm{sPE})$ ), and using peptide grouping, we propose a variant of such peptide panel with a high differentiating capacity, which consists of 22 peptide groups and also includes markers described earlier.

\section{Materials and Methods}

\subsection{Patients}

Patients were diagnosed in V.I. Kulakov's National Medical Research Center of Obstetrics, Gynecology and Perinatology in accordance with the ACOG Practice Bulletin (2002). PE was diagnosed at blood pressure $(\mathrm{BP})>140 / 90 \mathrm{mmHg}$, proteinuria $>0.3 \mathrm{~g} / \mathrm{L}$ daily, edema, manifestations of multisystem organ insufficiency. Severe PE was diagnosed with at least one of the following symptoms: $\mathrm{BP} \geq 160 / 100 \mathrm{mmHg}$ (twice within $6 \mathrm{~h}$ ); proteinuria $\geq 5 \mathrm{~g} / \mathrm{L}$ daily or $>0.3 \mathrm{~g} / \mathrm{L}$ in separate urine samples; oliguria $\leq 500 \mathrm{~mL} /$ day; epigastric pain and/or pain in right hypochondrium; pulmonary edema or pulmonary failure; more than twice increase in alanine aminotransferase (ALT) and aspartate aminotransferase (AST); neurological complications; thrombocytopenia (less than $100 \times 10^{9} / \mathrm{L}$ ); intrauterine growth restriction (IUGR) (fetal weight below 10 percentiles).

Normotensive pregnant women with urine protein content $<0.1 \mathrm{mg} / \mathrm{mL}$ were enrolled into the control group. The exclusion criteria included: multiple pregnancy, pregnancy after assisted reproductive technology (ART), diabetes, transplanted organs, autoimmune diseases, oncological diseases, decompensated kidney disease, chromosomal abnormalities in the fetus, congenital malformations of the fetus, and antenatal fetal death. $\mathrm{CH}$ and $\mathrm{GH}$ were diagnosed in patients who did not meet the PE criteria: $\mathrm{CH}$ in patients, who had hypertension before pregnancy; $\mathrm{GH}$ in patients with hypertension experienced during pregnancy.

In total, the study included 127 urine samples from 126 pregnant women: 17 from normotensive pregnant controls, 16 from patients with chronic arterial hypertension $(\mathrm{CH}$; two of the samples were obtained from one patient), 15 with gestational arterial hypertension (GH), 25 with mild PE (mPE), 25 with severe PE (sPE), and 29 samples were from patients with complicated diagnoses that were considered to be unrelated to any group. The latter included 14 samples from patients with $\mathrm{PE}$ superimposed on $\mathrm{CH}$ (PE-CH); 4 samples from patients diagnosed as $\mathrm{CH}$ with suspected $\mathrm{PE} ; 1$ sample from the patient with GH who later developed $\mathrm{mPE}$ and sPE; 1 sample with mPE superimposed on a non-hypertensive pathology; and 9 samples with suspected but not diagnosed PE. Clinical and demographical data are shown in Table 1.

In the intergroup analysis incidence of hypertension in family history in $\mathrm{PE}, \mathrm{CH}$ and $\mathrm{PE}-\mathrm{CH}$ did not differ statistically between the groups- $46.4 \%, 50 \%$, and $50 \%$, correspondingly-but was significantly more common as compared to the control group: $20 \%(p<0.01)$. Thus, hypertension in relatives is a risk factor for hypertensive disorders in pregnancy. In the PE group, women were significantly more likely to have had adverse pregnancy outcomes: antenatal fetal death $(7.1 \%)$, early neonatal death (3.6\%), and history of preeclampsia (17.9\%) compared to women with PE superimposed on $\mathrm{CH}(0 \%, 0 \%$, and $12.5 \%$, respectively), and to the control group where these complications were not observed $(p<0.05)$. 
Table 1. Clinical and demographic data of patients.

\begin{tabular}{|c|c|c|c|c|c|}
\hline Parameter & $\begin{array}{l}\text { Control } \\
(n=17)\end{array}$ & $\begin{array}{c}\text { CAH } \\
(n=15)\end{array}$ & $\begin{array}{c}\text { GAH } \\
(n=15)\end{array}$ & Mild PE $(n=25)$ & $\begin{array}{c}\text { Severe PE } \\
(n=25)\end{array}$ \\
\hline Age (years) & $30.5 \pm 4.1$ & $31.8 \pm 5$ & $32.6 \pm 4.2$ & $28.5 \pm 4.2$ & $32.2 \pm 4.5$ \\
\hline Height $(\mathrm{cm})$ & $168.6 \pm 4.8$ & $167.4 \pm 5$ & $166.8 \pm 7.1$ & $164.6 \pm 5.2$ & $163.9 \pm 5.8$ \\
\hline Weight (kg) & $70.1 \pm 8.3$ & $83 \pm 15.5$ & $76.5 \pm 10.3$ & $76.1 \pm 14.9$ & $74.2 \pm 14.2$ \\
\hline BMI $\left(\mathrm{kg} / \mathrm{m}^{2}\right)$ & $24.7 \pm 3.1$ & $28.6 \pm 3.4$ & $27.2 \pm 3.1$ & $28.1 \pm 5$ & $27.6 \pm 5.1$ \\
\hline Kidney disease & $2(11.1 \%)$ & $2(10.5 \%)$ & $4(25 \%)$ & $2(7.7 \%)$ & $4(15.4 \%)$ \\
\hline Previous PE & $1(5.6 \%)$ & $6(31.6 \%)$ & $1(6.2 \%)$ & $0(0 \%)$ & $6(23.1 \%)$ \\
\hline Primiparous & $5(27.8 \%)$ & $7(36.8 \%)$ & $5(31.2 \%)$ & $16(61.5 \%)$ & $11(42.3 \%)$ \\
\hline Start of hypertension (days) & - & $28 \pm 9.1$ & $29.2 \pm 5.4$ & $34.3 \pm 5.1$ & $28.2 \pm 8.2$ \\
\hline Start of proteinuria (days) & - & $36.5 \pm 0.7$ & $33.5 \pm 0.2$ & $36.7 \pm 2.1$ & $32 \pm 4.6$ \\
\hline sFlt-1/PLGF & $6.7 \pm 1.8$ & $33.4 \pm 31.1$ & $67.8 \pm 78.1$ & $229.8 \pm 209.6$ & $346.3 \pm 281.9$ \\
\hline Delivery (weeks) & $39 \pm 1.1$ & $37.8 \pm 1.9$ & $37.6 \pm 2.2$ & $37.9 \pm 1.6$ & $33.6 \pm 4.4$ \\
\hline Maximal SP & $117.2 \pm 5.5$ & $143.1 \pm 14.4$ & $146.7 \pm 10.9$ & $151.5 \pm 12.6$ & $157.7 \pm 11.3$ \\
\hline Maximal DP & $77.8 \pm 3.9$ & $90.9 \pm 7.3$ & $94.7 \pm 8.9$ & $96.0 \pm 6.9$ & $100.8 \pm 7.5$ \\
\hline Maximal Pu (g/l) & $0 \pm 0$ & $0.1 \pm 0.1$ & $0.1 \pm 0.1$ & $1.2 \pm 1.0$ & $2.3 \pm 1.6$ \\
\hline LDH & $393.3 \pm 0$ & $327.6 \pm 14.4$ & $366.2 \pm 33.8$ & $334.5 \pm 91.0$ & $445.8 \pm 117.1$ \\
\hline ALT & $13.8 \pm 2.2$ & $15 \pm 6.6$ & $17.9 \pm 7$ & $24.6 \pm 28.7$ & $36.1 \pm 20.1$ \\
\hline AST & $17.3 \pm 3.4$ & $18.9 \pm 4.6$ & $16.8 \pm 4.8$ & $25.0 \pm 12.2$ & $33.9 \pm 15.7$ \\
\hline ALP & $129.7 \pm 3.4$ & $201 \pm 156.3$ & $164.3 \pm 68.3$ & $168.5 \pm 47$ & $183.2 \pm 89.2$ \\
\hline Platelet count & $217.3 \pm 56.5$ & $244.1 \pm 73.4$ & $251.5 \pm 55.2$ & $218.8 \pm 67.8$ & $199.5 \pm 77.2$ \\
\hline UAPI & $0.9 \pm 0$ & $0.9 \pm 0.3$ & $1 \pm 0.3$ & $1.4 \pm 0.6$ & $2.0 \pm 1.0$ \\
\hline UMAPI & $0.9 \pm 0$ & $1.1 \pm 0.4$ & $1 \pm 0.3$ & $1.3 \pm 0.5$ & $1.6 \pm 1.3$ \\
\hline MCAPI & $1.6 \pm 0$ & $2.8 \pm 0.7$ & $1.8 \pm 0.3$ & $2.6 \pm 1.2$ & $2.8 \pm 1.1$ \\
\hline IUGR & $0(0 \%)$ & $0(0 \%)$ & $2(12.5 \%)$ & $6(23.1 \%)$ & $17(65.4 \%)$ \\
\hline Child weight (g) & $3361.8 \pm 505.7$ & $3035.3 \pm 518.6$ & $2961 \pm 562.5$ & $2768.3 \pm 540.5$ & $1783.3 \pm 834.4$ \\
\hline Child height $(\mathrm{cm})$ & $51.4 \pm 2.4$ & $50.5 \pm 2.6$ & $49.9 \pm 3.6$ & $48.8 \pm 2.6$ & $40.9 \pm 8$ \\
\hline Apgar 1 min & $8.1 \pm 0.3$ & $7.9 \pm 0.3$ & $7.8 \pm 0.5$ & $7.7 \pm 0.5$ & $6.6 \pm 1.7$ \\
\hline Apgar 5 min & $9.1 \pm 0.4$ & $8.7 \pm 0.6$ & $8.6 \pm 0.6$ & $8.7 \pm 0.5$ & $7.7 \pm 1.3$ \\
\hline
\end{tabular}

UAPI-uterine artery pulsatility index, UMAPI—fetal umbilical artery pulsatility index, MCAPI-fetal middle cerebral artery pulsatility index, $\mathrm{Pu}$-proteinuria, LDH—lactate dehydrogenase, IUGR—intrauterine growth restriction.

\subsection{Urine Sample Collection and Peptide Isolation}

Urine collection was performed before treatment after a written informed consent of participants in accordance with the protocol approved by the Ethical Committee (Record No12 from 17 November 2016) of V.I. Kulakov's National Medical Research Center of Obstetrics, Gynecology and Perinatology.

Urine samples were centrifuged $\left(2000 \mathrm{~g}, 10 \mathrm{~min}, 4{ }^{\circ} \mathrm{C}\right)$ within $20 \mathrm{~min}$ after collection, and the supernatant was stored at $-80^{\circ} \mathrm{C}$. The peptide fraction was obtained as described earlier $[45,49]$. Particularly, $1.5 \mathrm{~mL}$ of urine was diluted with 3 volumes of denaturing buffer $(4 \mathrm{M}$ urea, $20 \mathrm{mM}$ ammonium hydroxide, $0.2 \%$ sodium dodecyl sulfate), transferred to Vivaspin- $410 \mathrm{kDa}$ MWCO (Sartorious) filters and centrifuged at $4000 \mathrm{~g}$ for $20 \mathrm{~min}$ at room temperature. The filtrate $(2.5 \mathrm{~mL})$ was further subjected to gel-filtration on a PD-10 Column (GE Healthcare; Sephadex ${ }^{\mathrm{TM}}$ G-25 Medium, equilibration and elution with $0.01 \%$ ammonium hydroxide). An amount of $2 \mathrm{~mL}$ of the eluate was lyophilized and dissolved in $100 \mu \mathrm{l}$ of deionized water prior to analysis. 


\subsection{HPLC-MS/MS Analysis}

HPLC-MS/MS analysis was performed on a nano-HPLC Agilent 1100 system (Agilent Technologies, Santa Clara, CA, USA) using a homemade capillary column (id $75 \mu \mathrm{m} \times$ length $12 \mathrm{~cm}$, Reprosil-Pur Basic C18, 3 m , 100 A; Dr. Maisch HPLC GmbH, Ammerbuch-Entringen, Germany) in combination with a 7-Tesla LTQ-FT Ultra mass spectrometer (Thermo Electron, Bremen, Germany) equipped with an in-house nanospray ion source. Gradient chromatography was implemented by changing the relative concentration of solvent B (100\% acetonitrile/ $0.1 \%$ formic acid) in flow of solvent $\mathrm{A}(0.1 \%$ formic acid). Main elution time was $15-45$ min: linear gradient from $3 \%$ to $50 \%$ of solvent B, elution of most hydrophobic peptides was 45-50 min: linear gradient from 50\% to $90 \%$ of solvent B. Each sample was analyzed in 4 runs.

\subsection{Urinary Proteome Data Base Development}

To facilitate the search procedure, a small data base was created for identification and semiquantitative analysis of the massive HPLC-MS/MS data (see below) using available computing power. The detailed description of the urinary proteome data base development is out of the scope of this manuscript. Briefly, to develop the data base, proteome analysis was performed for three pooled urine samples and their 10 fractions prepared by Isoelectic Focusing Electrophoresis (IEF) using the PROTEAN system (Bio-Rad). Pooled samples were prepared from 60 individual samples (10-Control, 10-GH, 10-CH, 10-(PE-CH), 10-mPE, 10-sPE) which were used for proteome and peptidome analysis. All samples were measured on a Q-Exactive HF operating in data dependent (DDA) mode. In total, 8423 tryptic peptides from 1029 protein groups were identified and archived into the library. In an attempt to increase the coverage of the library, additional 95 individual samples (from 127 patients-2.1. Patients) were selected for additional proteomic analysis and measured in data independent (DIA) mode. Overall, this resulted in a spectral library containing 11,131 peptide ions and 1472 proteins, 32\% and $43 \%$ more than the initial DDA library, respectively. Finally, the database was expanded with preliminary peptide search data and peptides described previously in PE [42-47].

\subsection{Data Analysis}

Urinary peptides were identified using PEAKS Studio 8.5 and MaxQuant (version 1.6.7.0) search programs across the developed urinary proteome data base (see above) with the following parameters: non-specific enzyme; mass accuracy for the precursor ion-20ppm; mass accuracy for MS/MS fragments-0.50 Da; possible variable modification-oxidation of methionine, lysine, and proline residues: up to 5 variable modifications per peptide, minimal peptide length was set to 5 amino acid residues, maximal peptide weight $-10 \mathrm{kDa}$, false discovery rate (FDR) $\leq 0.01$, minimal score for unmodified peptides-30, for modified-40. For semiquantitative label-free analysis, alignment of chromatograms was used; the particular peptide peak intensity values were normalized to the total intensity of all peaks in a particular sample. Significant differences in the representation of peptides in different patient groups were estimated using the Mann-Whitney U-test. The Venn diagram was build using the http://bioinformatics.psb.ugent.be/webtools/Venn/ resource, and heat-maps were created with the http://heatmapper.ca/ resource [50].

Multivariate data analysis of the semiquantitative proteomic data was performed using partial least squares analysis (PLS) with the ropls package [51] to create a classification model: normotensive pregnancy (control), hypertension without PE (CH and GH) and PE (mild and severe). The $Y$ variables for PLS model training were set from 1 to 3 for samples of different groups (specified in Figures). The quality of statistical models was estimated by R2 (fraction of data that the model can explain using the latent variables) and Q2 (fraction of data predicted by the model according to the cross validation) parameters. The model performance was assessed by calculating the area under receiver operating characteristic curve (AUC). 


\section{Results}

\subsection{Urine Peptidome Analysis}

Analysis of MS data obtained for 127 samples allowed the identification of a total of 3869 peptides with FDR $<0.1 \%$ from 43 proteins when using the PEAKS program for identification (Table S1). However, a much smaller number of peptides was found to be substantially represented in at least one of the diagnostic groups: calculation of the median intensity values revealed only 340 (including PTM variations) substantially represented peptides, whose medians exceeded the "zero" level (Table 2 and S2).

Table 2. Number and origin of substantially represented peptides in urine of pregnant women ( $\mathrm{CH}$-chronic hypertension; $\mathrm{GH}$ — gestational hypertension; Mpe-mild preeclampsia; sPE—severe preeclamsia).

\begin{tabular}{|c|c|c|c|}
\hline Originating Protein & Number of Peptides & Number of Samples ${ }^{a}$ & Diagnostic Groups b,c \\
\hline COL1A1 & 196 & 127 & All groups \\
\hline COL3A1 & 80 & 127 & All groups \\
\hline COL1A2 & 10 & 110 & All groups \\
\hline UMOD & 10 & 102 & All groups \\
\hline FGA & 9 & 121 & All groups \\
\hline COL18A1 & 8 & 122 & Contr, $\mathrm{CH}, \mathrm{GH}, \mathrm{mPE}, \mathrm{sPE}$ \\
\hline KISS1 & 4 & 58 & $\mathrm{CH}, \mathrm{GH}, \mathrm{mPE}$ \\
\hline COL4A4 & 3 & 74 & Contr, $\mathrm{CH}, \mathrm{GH}, \mathrm{mPE}$ \\
\hline FGB & 2 & 90 & Contr, $\mathrm{CH}, \mathrm{GH}, \mathrm{mPE}$ \\
\hline COL2A1 & 2 & 74 & Contr, $\mathrm{CH}, \mathrm{GH}, \mathrm{mPE}$ \\
\hline EMID1 & 2 & 74 & Contr, $\mathrm{CH}, \mathrm{GH}, \mathrm{mPE}$ \\
\hline COL5A1 & 2 & 48 & $\mathrm{CH}, \mathrm{GH}, \mathrm{mPE}$ \\
\hline COL8A1 & 2 & 43 & $\mathrm{CH}, \mathrm{GH}$ \\
\hline COL15A1 & 1 & 74 & Contr, $\mathrm{CH}, \mathrm{GH}, \mathrm{mPE}$ \\
\hline COL17A1 & 1 & 74 & Contr, $\mathrm{CH}, \mathrm{GH}, \mathrm{mPE}$ \\
\hline FXYD2 & 1 & 59 & Contr, $\mathrm{mPE}$ \\
\hline PGRMC1 & 1 & 49 & $\mathrm{CH}$ \\
\hline VGF & 1 & 49 & $\mathrm{CH}, \mathrm{GH}$ \\
\hline INS & 1 & 47 & $\mathrm{CH}, \mathrm{GH}$ \\
\hline KDM6B & 1 & 42 & sPE \\
\hline PIGR & 1 & 31 & $\mathrm{GH}$ \\
\hline
\end{tabular}

${ }^{a}$ Values for the most represented peptides are given. ${ }^{b}$ Only diagnostic groups for which the median intensity values were above zero for at least one peptide from the corresponding protein are indicated. ${ }^{c}$ Gray background indicates consistent data for PEAKS and MaxQuant search programs.

Data in Table 1 indicates that the vast majority of substantially represented peptides are derived from collagen alpha-1(I) (COL1A1) and alpha-1(III) (COL3A1) chains. Single peptides from membrane-associated progesterone receptor (PGRMC1), neurosecretory protein VGF, insulin (INS), and lysine-specific demethylase 6B (KDM6B) are of particular interest as they have a predominant distribution in the hypertensive or PE groups. It is important to note that MaxQuant results are mostly consistent with those of PEAKS (Table 2, S3 and S4); however, PEAKS de novo sequencing is a definite advantage that essentially expands its identification capabilities. So, further analysis was mainly performed on the PEAKS data.

Unexpectedly, none of the SERPINA1 peptides demonstrated a substantial presence in any of the groups, although to date, their presence in urine of pregnant women has been considered as the main PE marker [42,45]. Nevertheless, the total number of identified SERPINA1 peptides (506 of $3869)$ is in third place after COL1A1 and COL3A1 ones (1493 and 917, correspondingly, Table S1). 
This suggests that SERPINA1 peptides are actually substantially represented, but their excision sites are highly variable. At the same time, the mostly represented SERPINA1 peptides (up to 37 samples, Table S1) were found to correspond to the C-terminus and have overlapping sequences. Therefore, it was suggested that combining peptides with overlapping sequences could take SERPINA1 peptides into consideration, as well as essentially expand the number of differentiating peptides. For this, we further considered peptide groups and compared the summed intensities of overlapping peptides.

\subsection{Peptide Groups}

The initial 3869 peptides (PEAKS) were subdivided into 116 groups (loci) in accordance with the overlapping sequences (Table S5), and 62 of these groups were found to be substantially represented in at least one patient group (Figure 1, Table 3). Interestingly, these substantial groups mostly originate from the proteins mentioned in Table 2, and only one COL5A1 and one SERPINA1 (C-terminal) loci were added. The number of samples, in which a particular peptide group was identified, increased in comparison with corresponding individual peptides (Table 3). It seems very important that the peptide group distribution mainly coincides with the distribution of individual essentially represented peptides, and thus suggests that consideration of peptides with overlapping sequences as one group is quite reasonable, especially since it allows information from a significantly higher number of peptides to be taken into account.

A

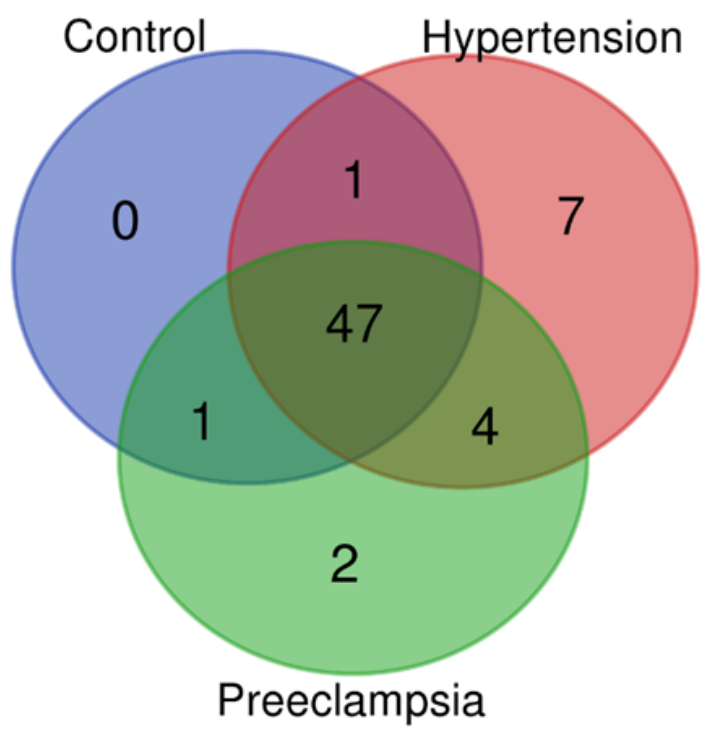

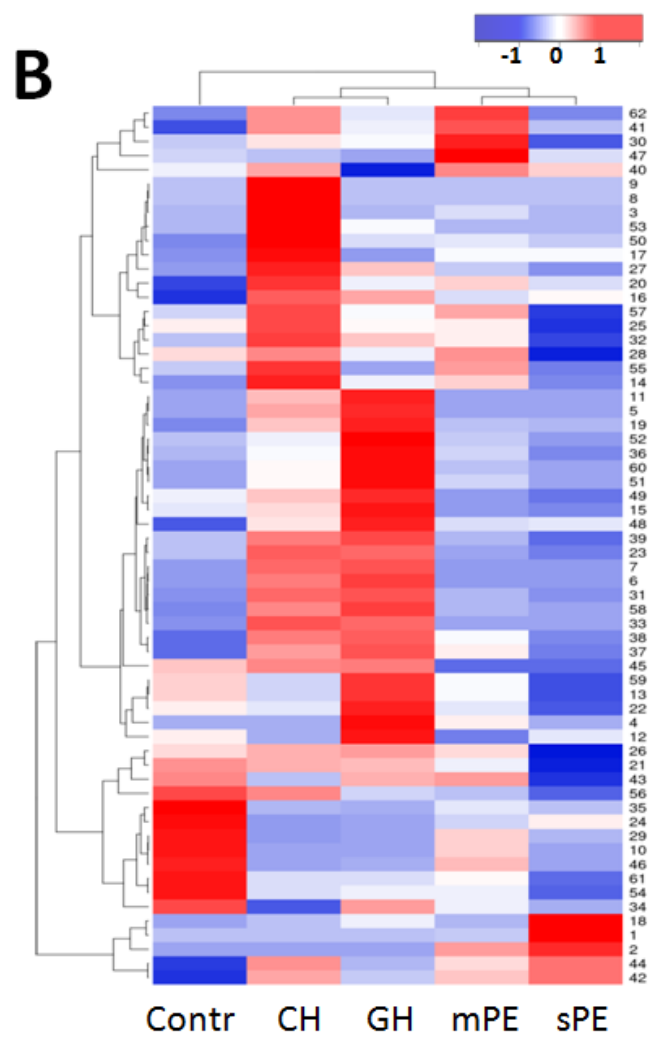

Figure 1. The distribution of 62 substantially represented peptide loci in control, hypertension $(\mathrm{CH}$ and $\mathrm{GH}$ ), and preeclampsia (mPE and sPE) patient groups. (A) Venn diagram demonstrating peptide group intersections. (B) Hierarchical clustering of the peptide loci's median intensity values and pregnancy associated hypertensive disorders groups. The Kendal's Tau distance measurement method and average linkage clustering were used. The higher values are shown in red, the lower-in blue. 
Table 3. Protein affiliation of the 62 substantial peptide groups in urine of pregnant women.

\begin{tabular}{|c|c|c|c|c|c|c|c|}
\hline \multirow{2}{*}{$\begin{array}{l}\text { Originating } \\
\text { Protein }\end{array}$} & \multirow{2}{*}{$\begin{array}{l}\text { Number of } \\
\text { Samples * }\end{array}$} & \multicolumn{6}{|c|}{$\begin{array}{l}\text { Intersection in Venn Diagram } \\
\text { Number of Peptide Groups }\end{array}$} \\
\hline & & Core & $\begin{array}{l}\text { Control/ } \\
\mathrm{CH}+\mathrm{GH}\end{array}$ & $\begin{array}{c}\text { Control/ } \\
\text { PE }\end{array}$ & $\begin{array}{c}\mathrm{CH}+\mathrm{GH} / \\
\mathrm{PE}\end{array}$ & $\mathrm{CH}+\mathrm{GH}$ & PE \\
\hline \multicolumn{2}{|c|}{ Intersection } & 47 & 1 & 1 & 4 & 7 & 2 \\
\hline UMOD & $118(102)$ & 1 & - & - & - & - & - \\
\hline KISS1 & $85(58)$ & 1 & - & - & - & - & - \\
\hline EMID1 & $103(74)$ & 1 & - & - & - & - & - \\
\hline FGA & $122(121)$ & 1 & - & - & - & - & - \\
\hline FGB & $95(90)$ & 1 & - & - & - & - & - \\
\hline COL2A1 & $106(74)$ & 1 & - & - & - & - & - \\
\hline COL8A1 & $93(43)$ & 1 & - & - & - & - & - \\
\hline COL15A1 & $92(74)$ & 1 & - & - & - & - & - \\
\hline COL17A1 & $93(74)$ & 1 & - & - & - & - & - \\
\hline COL3A1 & $127(127)$ & 14 & 1 & - & - & - & - \\
\hline COL1A1 & 127 (127) & 16 & - & - & 1 & - & - \\
\hline COL18A1 & $125(122)$ & 2 & - & - & 1 & - & - \\
\hline COL1A2 & $114(110)$ & 5 & - & - & - & 1 & - \\
\hline COL4A4 & $106(74)$ & 1 & - & - & - & 1 & - \\
\hline FXYD2 & $59(59)$ & - & - & 1 & - & - & - \\
\hline PIGR & $57(31)$ & - & - & - & 1 & - & - \\
\hline COL5A1 & $53(48)$ & - & - & - & 1 & 1 & - \\
\hline COL5A2 & $48(-)$ & - & - & - & - & 1 & - \\
\hline INS & $50(47)$ & - & - & - & - & 1 & - \\
\hline VGF & $52(49)$ & - & - & - & - & 1 & - \\
\hline PGRMC1 & $51(49)$ & - & - & - & - & 1 & - \\
\hline KDM6B & $62(42)$ & - & - & - & - & - & 1 \\
\hline SERPINA1 & $47(-)$ & - & - & - & - & - & 1 \\
\hline
\end{tabular}

* Given values correspond to the most represented peptide groups; values in brackets indicate the numbers corresponding to the most represented peptides originating from each protein (data from Table 2).

The data in Table 3 indicate that the bulk of the peptide loci is represented in all patient groups and belongs to the core, which mostly includes collagen (COL1A1, COL3A1, and others), KISS1, EMID1, fibrinogen, and uromodulin peptides. The heat-map in Figure 1B, however, suggests the essential differences in the percentage of these core loci in samples with different diagnoses. Single peptide groups from PGRMC1, VGF, insulin, and COL5A2 are substantially represented in CH and GH samples. The group of KDM6B peptides is substantially present in PE samples, like SERPINA1 peptides. It is noteworthy that consideration of overlapping peptides together as a single group essentially increased the number of samples with accounted KDM6B peptides (from 42 to 62), and reinforced the indication that these peptides could be potential PE markers.

Pairwise data comparison for all sample groups using the Mann-Whitney U-test revealed a significantly different distribution for 52 of the 62 peptide loci (Table S6). No significant difference was shown for 4 loci from COL3A1, 3 of COL1A2, as well as single EMID1, FXYD2, and uromodulin groups. Among the significantly differentiating peptide groups, 17 seem to be especially characteristic for the control, hypertensive, or PE samples, according to their $p$-values (Table S6, Figure 2).

The clustering in Figure 2 shows a good trend in the distribution of samples in accordance with the clinical diagnoses. This suggests that these urinary peptide groups can be considered as an appropriate basis for further development of a PE diagnostic panel. 


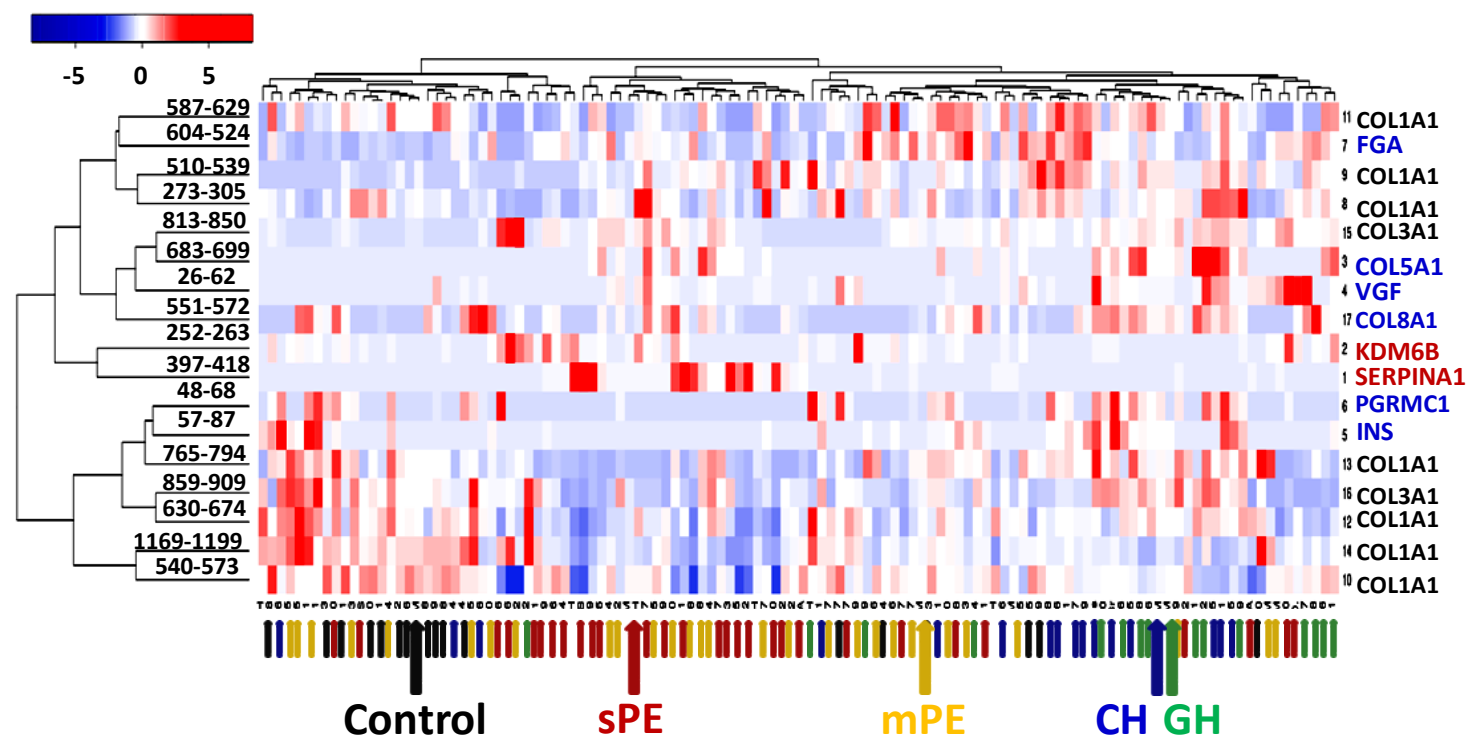

Figure 2. Hierarchical clustering of individual sample data and 17 characteristic peptide groups using Kendal's Tau distance measurement method and average linkage clustering. The small colored arrows indicate the clinical diagnosis in each particular sample; the large arrows show the median data of the corresponding patient groups: black—control, blue- $\mathrm{CH}$, green $-\mathrm{GH}$, yellow-mPE, and red-sPE.

\subsection{Predictive Performance and Model for PE Differentiation}

The PLS method was further applied to build a statistical model differentiating PE from hypertensive and control groups. In the beginning, the set of 570 individual peptides represented in at least 15 samples (Table S7) was analyzed to estimate whether some of potentially differentiating peptides could be lost upon selection of substantially represented peptides (and their groups). The clustering of three sample groups (control versus $\mathrm{CH}+\mathrm{GH}$ versus $\mathrm{PE}$ ) on these 570 peptides revealed 103 VIP-peptides, which give the largest contribution to the projection on hidden structures (Table S8), of which only the peptide 323-339 from alpha-2-HS-glycoprotein (AHSG) did not fall into consideration in the field of view above. Therefore, its peptide group was also taken into account and further PLS analysis was performed for 63 peptide loci (Table S5). Multiple clustering with different combinations of samples revealed the best parameters for combinations "Control+CH+GH versus $\mathrm{mPE}$ versus sPE" and "CH+GH versus mPE versus sPE" (Figure $3 \mathrm{~A}, \mathrm{~B}$ ). The comparison of VIP-peptide groups obtained upon multiple clustering showed that 22 of them were most often selected as VIPs upon clustering of different combinations of samples (Table 4). They included 15 different collagen loci as well as single groups from SERPINA1, KDM6B, INS, PGRMC1, EMID1, FGA, and AHSG; 13 of them were also part of the set of 17 selected in the previous section (Figure 2). Clustering by these 22 peptide loci showed the best parameters for differentiating $\mathrm{mPE}$ and sPE from "Control+CH+GH", while the best parameters for PE differentiation from hypertensive samples only $(\mathrm{CH}+\mathrm{GH})$ was obtained with only 20 of these groups (excluding loci "540-573" and "798-812" of COL1A1, Table 4).

\subsection{PE Markers}

SERPINA1-derived peptides are currently one of the main commonly accepted urine PE markers $[42,45,47,52,53]$. It is noteworthy that among the 3869 peptides identified in this study, 506 derived from SERPINA1. In accordance with their sequences, they can be grouped into 11 loci (Table S5) and cover $64.8 \%$ of the full sequence. Although the C-terminal locus (397-418) was shown to be the only one substantially represented in PE-samples, C-terminal peptides were also found in 2 $\mathrm{CH}$ samples and 16 samples with complicated diagnoses. From the $50 \mathrm{PE}$-samples, these $\mathrm{C}$-terminal peptides were found in 28 ( $14 \mathrm{mPE}$ and $14 \mathrm{sPE}$ ), and only $2 \mathrm{PE}$ samples contained other SERPINA1 peptides while missing the C-terminal locus. At the same time, peptides from other SERPINA1 
groups though each was met in only a small number of samples, were found in PE samples only, thus suggesting that identification of all SERPINA1 peptides may still remain reasonable for PE diagnosis. However, 20 of the PE samples (40\%) did not contain any SERPINA1 peptides and required other diagnostic marker(s).

\section{A (Control+CH+GH) vs. mPE vs. sPE}

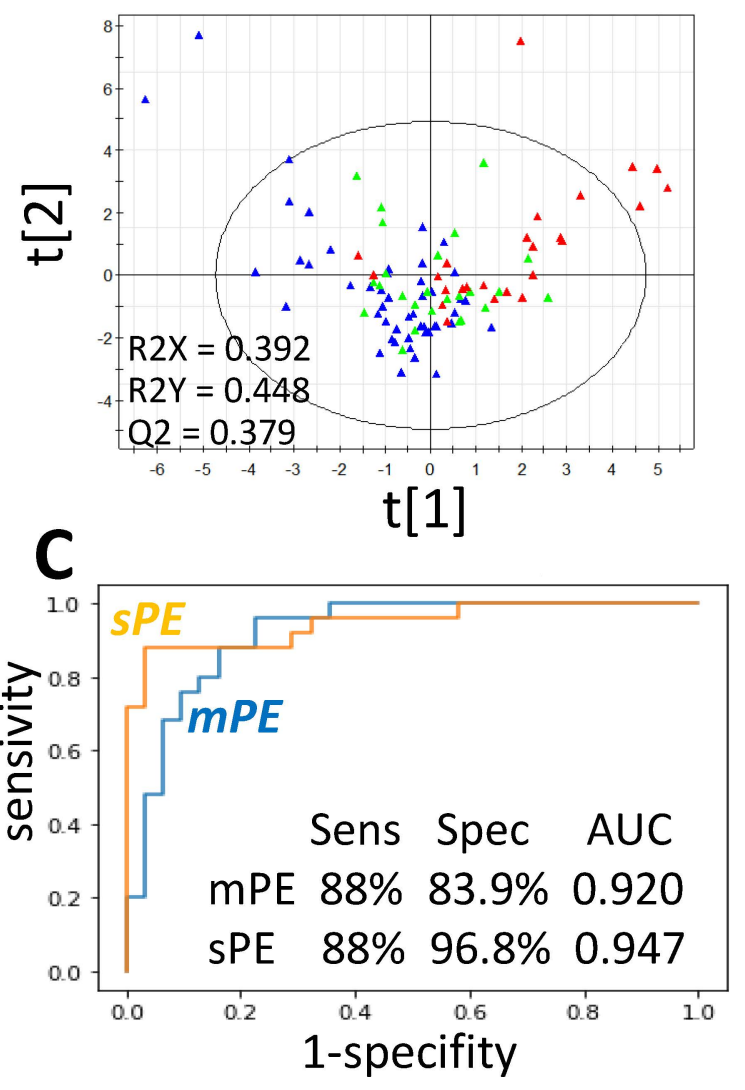

\section{B (CH+GH) vs. mPE vs. SPE}
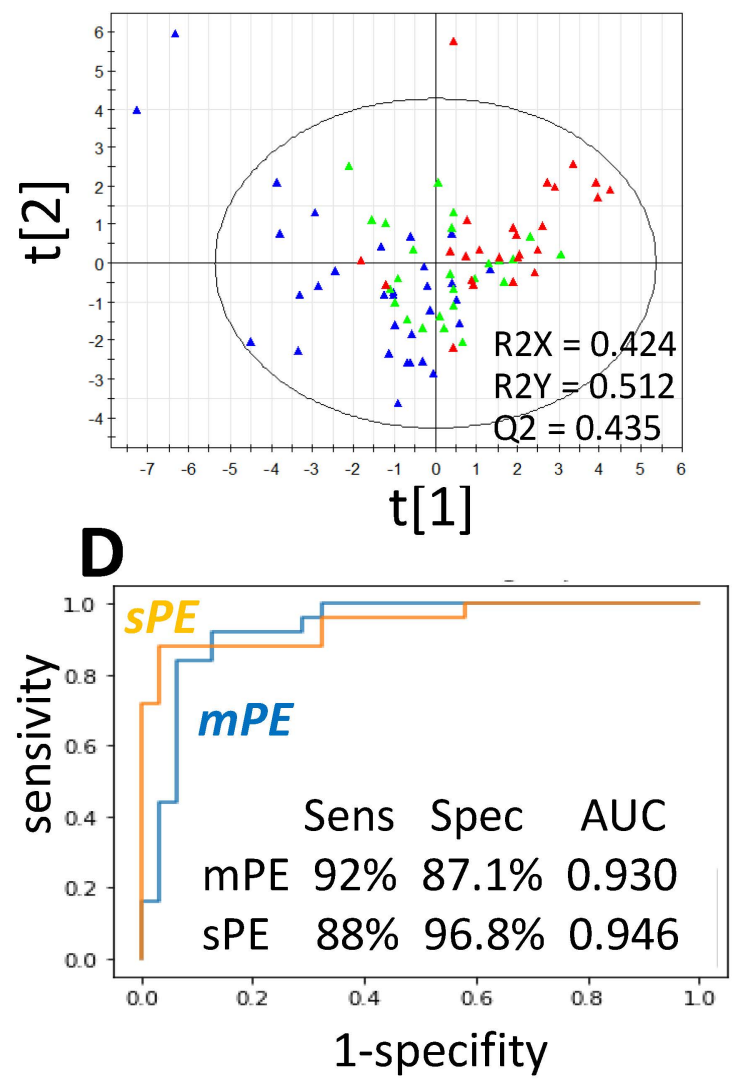

Figure 3. PLS model differentiating $\mathrm{mPE}$ and $\mathrm{sPE}$ urine samples from control, $\mathrm{CH}$, and $\mathrm{GH}$ samples. (A,B) PLS score plot of semiquantitative urinary peptidomic data: blue- "Control+CH+GH" (A) or "CH+GH" (B); green-mPE; red-sPE. (C,D) ROC analysis for mPE or sPE versus "Control+CH+GH" (C) or "CH+GH" (D) according to the results of clustering on 22 and 20 VIP-peptide groups (for $\mathbf{C}$ and D, correspondingly).

The KDM6B-derived poly-proline peptides 252-257/263 may be another PE-marker as they show predominant significantly different distribution in PE patient groups (in $16 \mathrm{mPE}$ and $17 \mathrm{sPE}$ samples). The data in Figure 4 implicate that together SERPINA1 and KDM6B peptides identify 47 of the 50 PE samples. However, KDM6B peptides demonstrated lower specificity in comparison with SERPINA1 and were also found in $25 \%$ normotensive and $\mathrm{CH}$ samples and in $46.7 \%$ GH samples. Nevertheless, the poly-proline peptide group is the essential integral component of the described above differentiating panel.

The AHSG peptide group 321-339 is one another possible PE marker. Although it is much less represented, only in $8 \mathrm{mPE}$ and $10 \mathrm{sPE}$ samples, it seems to be rather specific. However, these peptides were found only in samples, which also contained SERPINA1 or poly-proline KDM6B peptides, and did not increase the total number of identified PE samples (Figure 4). Nevertheless, this peptide group also deserves particular attention due to its selection into PLS-VIPs (Table 4). 
Table 4. Urine VIP-peptide groups mostly differentiating $\mathrm{mPE}$ and $\mathrm{sPE}$ from control, $\mathrm{CH}$, and GH samples.

\begin{tabular}{|c|c|c|c|c|}
\hline Peptide Group & $\begin{array}{l}\text { Start-End } \\
\text { Position }\end{array}$ & $\begin{array}{c}\text { Originating } \\
\text { Protein }\end{array}$ & $\begin{array}{c}\text { Number of } \\
\text { Samples }\end{array}$ & $\begin{array}{c}\text { Other } \\
\text { Studies }\end{array}$ \\
\hline GAAGEPGKAGERGVPGPPGAVGPAGKDGEAGAQGPPGPAGPAG & $587-629$ & COL1A1 & 114 & \\
\hline EAEDLQVGQVELGGGPGAGSLQPLALEGSLQ & $57-87$ & INS & 50 & \\
\hline LMIEQNTKSPLFMGKVVNPTQK & 397-418 & SERPINA1 & 47 & {$[42,45]$} \\
\hline ERGSPGPAGPKGSPGEAGRPGEAGLPGAKG & $510-539$ & COL1A1 & 98 & [44] \\
\hline LLGPKGPPGPPGPPGVT & 683-699 & COL5A1 & 39 & \\
\hline GRDGEPGTPGNPGPPGPPGPPGPPG & $150-174$ & COL2A1 & 106 & \\
\hline GPAGPPGPPGPPGTSGHPGSPGSPGYGPPGEPGQAGPSGPPG & 174-216 & COL3A1 & 113 & \\
\hline GQPGPPGPPGPPG & $1021-1033$ & COL4A4 & 49 & \\
\hline AGPPGRDGIPGQPGLPGPPGPPGPPGPPGLGGN & 126-158 & COL1A1 & 116 & \\
\hline GPQGQPGLPGPPGPPGPPGPPA & $551-572$ & COL8A1 & 93 & \\
\hline MGVVSLGSPSGEVSHPRKT & 321-339 & AHSG & 26 & \\
\hline GDQPAASGDSDDDEPPPLPRL & $48-68$ & PGRMC1 & 51 & \\
\hline ADEAGSEADHEGTHSTKRGHAKSRPV & 604-624 & FGA & 122 & [44] \\
\hline ERGEQGPAGSPGFQGLPGPAGPPGEAGKPGEQGVPGDLGAPGPSG & $630-674$ & COL1A1 & 127 & \\
\hline VKGERGSPGGPGAAGFPGARGLPGPPGSNGNPGPPGPSGSPGKDGPPGPAG & $859-909$ & COL3A1 & 125 & \\
\hline GERGPPGPPGRDGEDGPTGPPGPPGPPGPPGLGGNFA & $42-78$ & COL1A2 & 100 & \\
\hline LTGPIGPPGPAGAPGDKGESGPSGPAGPTG & 765-794 & COL1A1 & 110 & [44] \\
\hline РРРРРРРРРРРР & $252-263$ & KDM6B & 62 & \\
\hline LDGAKGDAGPAGPKGEPGSPGENGAPGQMGPRG & 273-305 & COL1A1 & 114 & \\
\hline PGERGPPGPPGPPGPPGPPAP & $241-260$ & EMID1 & 103 & \\
\hline LTGSPGSPGPDGKTGPPGPAGQDGRPGPPGPPGA & $540-573$ & COL1A1 & 127 & \\
\hline APGDRGEPGPPGPAG & 798-812 & COL1A1 & 126 & \\
\hline
\end{tabular}

The results of ROC-analysis (Figure 3C,D) suggest that the obtained VIP-peptide groups can be considered as a differentiating panel for PE diagnosis. It is noteworthy that the relative content of common peptide loci may have an essential PE differentiating capacity, in addition to the presence of particular marker peptides.

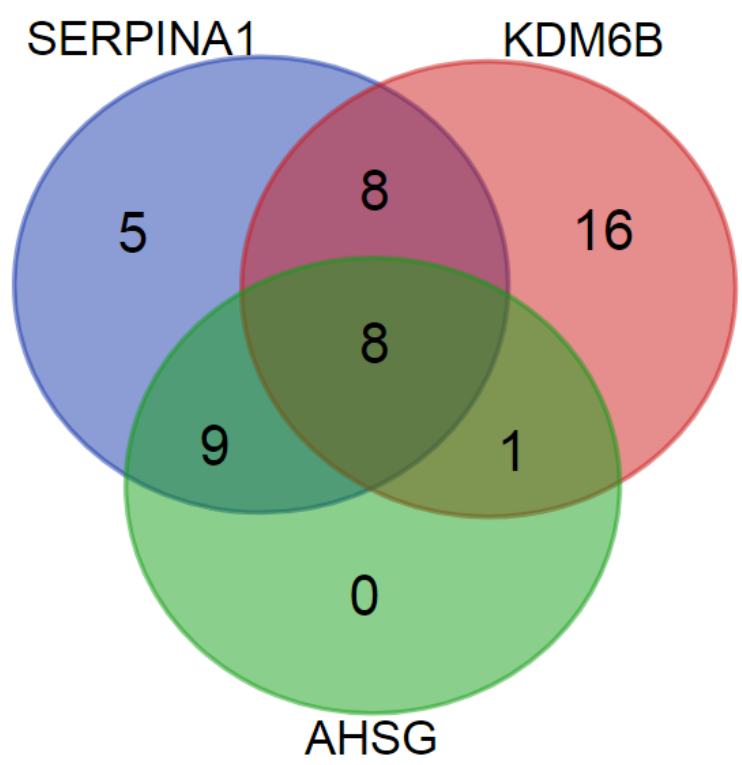

Figure 4. Distribution of SERPINA1, KDM6B, and AHSG peptides among 50 PE urine samples.

\subsection{Samples from Patients with Complicated Diagnoses}

MS data for 29 ungrouped samples were analyzed both for the presence of PE markers (peptides from SERPINA1, KDM6B, and AHSG) and for the characteristic clustering of VIP-peptide loci identified above. When diagnosed by markers, based on the data obtained for each patient group, the presence of SERPINA1 or AHSG peptides most likely indicated PE; sPE was highly probable if normalized intensity 
values for SERPINA1 C-terminal peptide locus exceeded "3". The KDM6B poly-proline peptide group could suggest PE if its normalized intensity values were higher than "0.1". For diagnosis with VIP-peptide groups, the data of ungrouped samples were co-clustered with the data of the grouped samples, which were used above for the identification of VIP-peptides. The particular co-clustering suggested the most likely diagnosis (Figure 5).

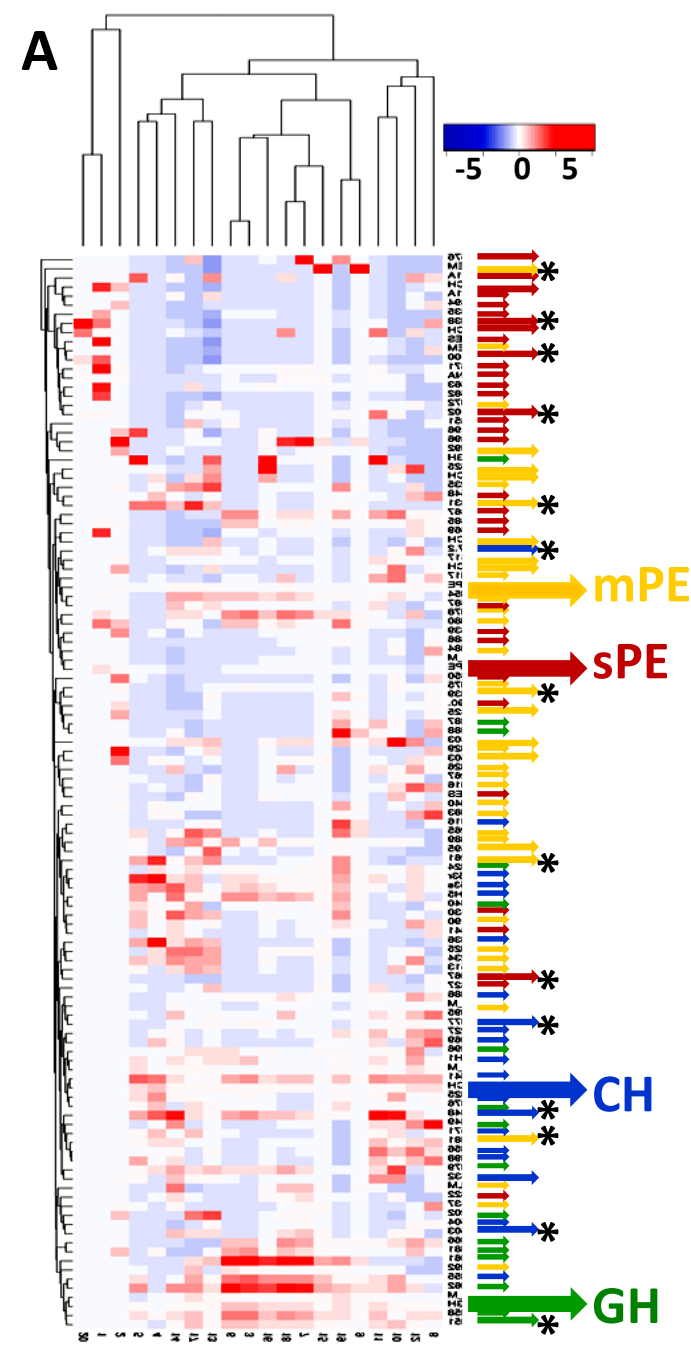

\section{B}

The ungrouped samples

\begin{tabular}{|c|c|c|c|}
\hline & \multicolumn{3}{|c|}{ Diagnosis } \\
\hline & Clinical & Markers & VIP-panel \\
\hline 1* & $\mathrm{mPE}$ & $?$ & SPE \\
\hline 2* & $\mathrm{CH}$ (PE) & $?$ & $\mathrm{CH}(\mathrm{GH})$ \\
\hline $3^{*}$ & $\mathrm{CH}(\mathrm{PE})$ & $\mathrm{mPE}$ & $\mathrm{mPE}$ \\
\hline 4* & $\mathrm{CH}$ (PE) & $\mathrm{mPE}$ & $\mathrm{CH}$ \\
\hline $5 *$ & $\mathrm{CH}$ (PE) & $\mathrm{mPE}$ & $\mathrm{CH}$ \\
\hline 6* & $\mathrm{GH} \rightarrow \mathrm{PE}$ & $\mathrm{mPE}$ & GH \\
\hline $7^{*}$ & SPE-CH & SPE & SPE \\
\hline $8^{*}$ & SPE-CH & SPE & $\mathrm{mPE}$ \\
\hline 9* & mPE-CH & $\mathrm{mPE}$ & $\mathrm{CH}$ \\
\hline $10 *$ & SPE-CH & SPE & SPE \\
\hline $11 *$ & SPE-CH & SPE & sPE \\
\hline $12^{*}$ & $\mathrm{mPE}-\mathrm{CH}$ & $\mathrm{mPE}$ & $\mathrm{mPE}$ \\
\hline $13 *$ & $\mathrm{mPE}-\mathrm{CH}$ & $\mathrm{mPE}$ & $\mathrm{mPE}$ \\
\hline $14^{*}$ & $\mathrm{mPE}-\mathrm{CH}$ & $\mathrm{mPE}$ & $\mathrm{mPE}$ \\
\hline 15 & $\mathrm{PE}-\mathrm{CH}$ & $?$ & $\mathrm{mPE} \rightarrow \mathrm{sPE}$ \\
\hline 16 & $\mathrm{PE}-\mathrm{CH}$ & ? & SPE \\
\hline 17 & $\mathrm{PE}-\mathrm{CH}$ & $?$ & $\mathrm{mPE}$ \\
\hline 18 & $\mathrm{PE}-\mathrm{CH}$ & $?$ & $\mathrm{mPE}$ \\
\hline 19 & $\mathrm{PE}-\mathrm{CH}$ & $?$ & SPE \\
\hline 20 & $\mathrm{PE}-\mathrm{CH}$ & $?$ & $\mathrm{mPE}$ \\
\hline 21 & $?$ & $?$ & SPE \\
\hline 22 & ? & $\mathrm{mPE}$ & $S P E$ \\
\hline 23 & $?$ & $\mathrm{mPE}$ & $\mathrm{mPE}$ \\
\hline 24 & $?$ & $\mathrm{mPE}$ & $\mathrm{mPE}$ \\
\hline 25 & $?$ & $\mathrm{mPE}$ & $\mathrm{mPE}$ \\
\hline 26 & $?$ & $\mathrm{mPE}$ & $\mathrm{mPE}$ \\
\hline 27 & $?$ & $\mathrm{mPE}$ & $\mathrm{CH}(\mathrm{GH})$ \\
\hline 28 & $?$ & $\mathrm{CH}-\mathrm{GH}$ & $\mathrm{mPE}$ \\
\hline 29 & $?$ & $\mathrm{CH}-\mathrm{GH}$ & $\mathrm{mPE}$ \\
\hline Coin & cidence & $67 \%$ & $90 \%$ \\
\hline
\end{tabular}

Figure 5. Co-clustering of ungrouped and grouped samples by 20 VIP-peptide groups. (A) Hierarchical co-clustering using Kendal's Tau distance measurement method and average linkage clustering. The small colored arrows indicate the established clinical diagnoses in grouped samples; the middle arrows without asterisks - the probable diagnoses of ungrouped samples (with asterisks — established clinical diagnoses for ungrouped samples); the large arrows show the mean data of corresponding patient groups: blue $-\mathrm{CH}$, green- $-\mathrm{GH}$, yellow-mPE, and red-sPE. (B) The comparison of clinical diagnoses with diagnoses proposed by using markers and VIP-peptide clustering. Grey background shows results consistent with clinical diagnoses (ignoring PE subdivision).

According to the results in Figure 5, VIP-peptide co-clustering is essentially more sensitive and specific than diagnosis by markers, since it gives $90 \%$ coincidence with clinical diagnoses and is able to differentiate any sample, whereas the markers give only a $67 \%$ coincidence and differentiate only 20 of the 29 samples.

The sample from the patient, who was clinically diagnosed as GH and further developed mPE and SPE (number $6^{*}$, green arrow with asterisk in Figure 5), is of particular interest, since the two later samples were also analyzed (and enrolled into $\mathrm{mPE}$ and sPE diagnostic groups). The illustrated in 
Figure 6 dynamic changes of the peptide profile and VIP-peptide groups for this patient suggest that in addition to a significant increase in PE markers, the significant decrease in the content of collagen, INS, PGRMC1, and other peptides has a quite pronounced tendency and may reflect PE severity as well as appearance in the profile of a large number of peptides originating from a variety of plasma proteins (such as APOA1, A1BG, HBB, and others).

\section{A Peptide profile}

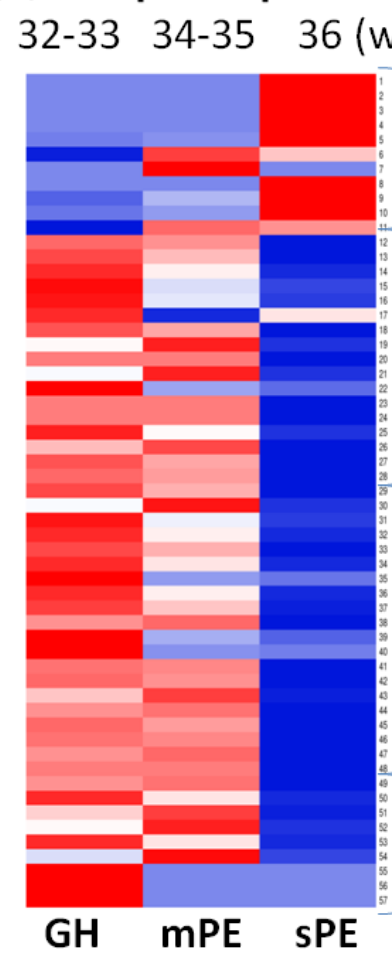

B VIP-peptides

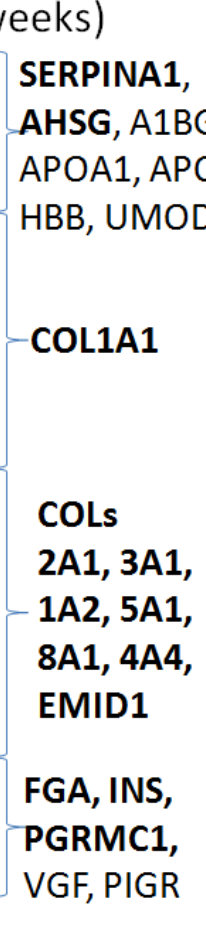

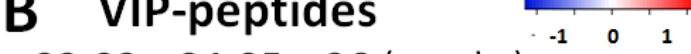

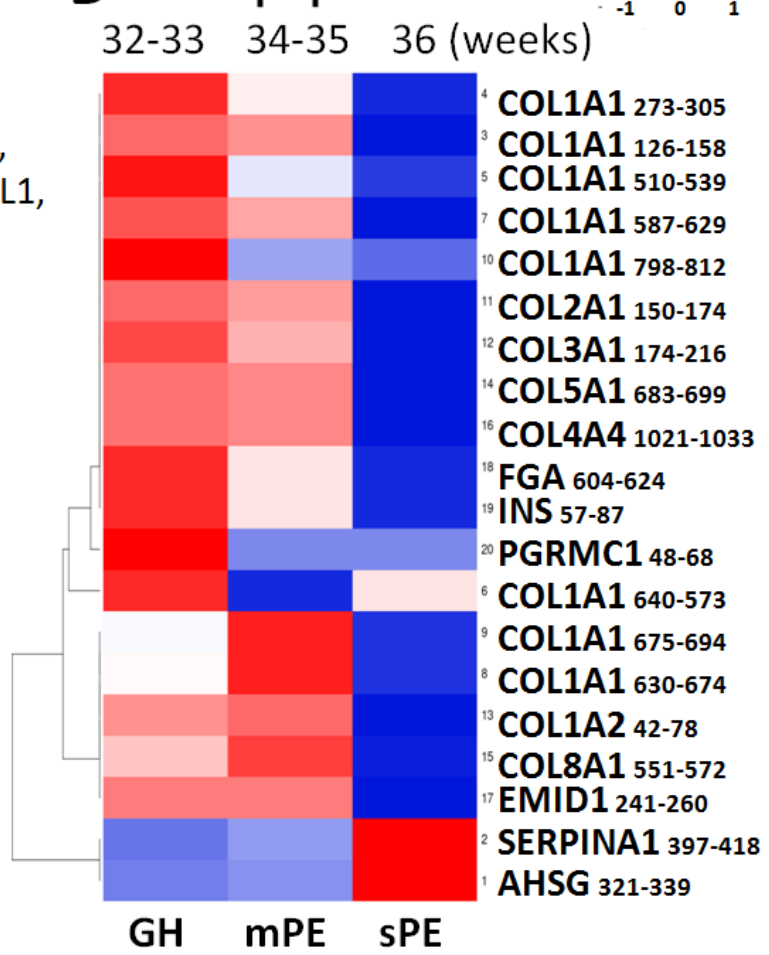

Figure 6. Dynamic urine peptidome changes upon GH progression into PE, on the example of three samples obtained from the same patient at different gestation ages. (A) Profiling of the most represented peptide groups (without clustering). (B) Hierarchical clustering of VIP-peptide groups found in the compared samples using Kendal's Tau distance measurement method and average linkage clustering.

Importantly, SERPINA1 peptides were found in all three samples of this (initially GH) patient, although their content was very significantly different (Table S9). The fact that VIP-peptide clustering still differentiated the first sample as GH in spite of the presence of SERPINA1 peptides (what coincided to the clinical diagnosis) once again implicates the high diagnostic capacity of the obtained VIP-panel. At the same time, in the example of this patient, it can be assumed that the appearance of SERPINA1 peptides in urine may indicate the increased risk of GH progression to PE.

In general, the results obtained with ungrouped samples from patients with complicated diagnosis suggest the essential diagnostic potential of the obtained VIP-peptide panel.

\section{Discussion}

Creation of a urine peptide panel for PE differentiation remains an urgent research task. In an attempt to create such a panel, a special strategy was applied in this study. Urine peptides with overlapping sequences were grouped and considered together as one locus and were found to have the same distribution as their most represented peptides. The combination of peptides seemed appropriate given that no specific cleavage sites and amino-acid modifications were detected for any diagnosis, at least in the analyzed 127 samples. It was assumed that peptide grouping and comparison of their summed normalized intensities should smooth out the insignificant differences of sequences and focus the attention on the presence of particular peptide locus and its relative content in samples 
with specific diagnoses. Additionally, this strategy might essentially decrease the discrepancies when measuring different series of samples and even reduce dissimilarities in the results of different studies. The obtained results suggested that the application of this strategy proved to be quite appropriate and led to the creation of a variant of a peptide panel, which differentiates PE with high sensitivity and specificity.

Among members of the obtained panel there are several coincidences with the results of other studies (Table 4). In particular, two COL1A1 groups, "510-539" and "765-794", and the FGA "604-624" locus contain peptides earlier described as PE markers by Carty D.M. et al. [44]. Among other substantially represented groups obtained here, COL1A1 "1007-1041"; COL3A1 "446-477", COL1A2 "451-472", and "917-952"; and the uromodulin locus also have coincidences with the results of [44]. However, here, they were not selected into VIP-groups, and moreover, the distribution of uromodulin peptides was not found to be significantly different (remarkably, all of the revealed uromodulin peptides belonged to the same locus "589-607"). It is noteworthy that all of these peptide groups (including 3 VIPs) were identified in most of the analyzed samples and, hence, their presence by itself is not a marker. Nevertheless, their relative content (and in particular the content of VIP-groups) proved to be extremely important for PE differentiation.

As for direct markers of PE, the obtained results support the findings of I.A. Buhimschi et al. concerning SERPINA1 peptides [42]. However, despite the wide variety of identified SERPINA1 peptides, only the C-terminal group was shown to have a diagnostic significance since it had the highest representation. Again, consideration of the C-terminal peptide locus "397-418" also proved to be advantageous compared to its most represented peptide (398-418) since the group was detected in 47 different samples, while the peptide itself in only 37 of them. However, SERPINA1 peptides were found in only $60 \%$ of PE samples and the rest required other markers.

Poly-proline (from 6 to 12 poly-P) peptides, SERPINA1 peptides, were found to be significantly distributed in PE patient groups and essentially enhanced PE differentiation; together with SERPINA1 peptides, poly-P covered $94 \%$ of PE samples. Unlike SERPINA1 peptides, poly-P peptides are not absolutely specific markers; nevertheless, their relative content is definitely an essential indicator, first identified in this study. The possible relation of KDM6B to PE is actually unclear, especially taking into account that this protein is associated with chromatin and localized in the nucleus. However, it was shown to be involved in the inflammatory response by participating in macrophage differentiation via the regulation of gene expression [54]. Since PE is usually associated with a systemic inflammation, it may be assumed that KDM6B peptides in urine may originate from the degraded macrophages. On the other hand, the appearance of KDM6B peptides may reflect the epigenetic regulation of compensatory mechanisms, which, in particular, may lead to changes in the expression level of different SERPINs [16]. In addition, poly-P peptides may actually have different origin. In particular, many cytosolic, membrane, and cytoskeletal proteins such as large proline-rich protein BAG6, WASP homolog-associated protein with actin, protein diaphanous homologm1, MAP3K4 kinase, Ras-associated and pleckstrin homology domains-containing protein 1, and junction-mediating and -regulatory protein contain poly-P motives and may be the source of poly-P peptides in cell degradation. Still, the mechanism underlying the increase in urine poly-P in PE remains questionable.

Among the PE markers identified in this study, AHSG seems to be the most doubtful, since it was found only in 26 of 127 samples. Additionally, there are several other peptide groups with similar representativeness that did not fall into the differentiating panel: apolipoprotein A1 "254-267" (28 mostly PE samples), complement C4-A "1423-1440" (27 samples except for controls), clusterin "390-423" (39 samples except for controls) and some other (Table S5). In general, it is important to note that $\mathrm{SPE}$ is often associated with a large variety of urine peptides originating from different plasma proteins, and these peptides may look highly PE-specific. Whether it is appropriate to consider all of such peptides as possible markers remains a question.

In sum, it is worth noting that the obtained differentiating panel for the most part consists of peptides that are represented in most samples of all diagnostic groups. The relative content of these 
peptides implicates the important criterion for diagnosis that is similar to the presence of specific markers. The panel still requires further validation and may be essentially reorganized. However, the differentiating role of the substantially represented peptides and their groups is expected to be the most promising.

\section{Conclusions}

High-resolution mass spectrometry applied for analysis of the peptidome of 127 patients including normotensive controls $(n=17)$, chronic hypertension $(n=16)$, gestational hypertension $(n=15)$, mild PE $(n=25)$, severe PE $(n=25)$, and 29 patients with complicated diagnosis reveal sample diversity and new features for PE diagnostics. A panel consisting of 22 peptide loci from collagens (COL1A1, COL3A1, COL2A1, COL5A1, COL8A1, and COL4A4), fibrinogen alpha-chain, insulin, membrane-associated progesterone receptor component 1 , EMI domain-containing protein 1, alpha-1-antitrypsin, lysine-specific demethylase 6B, and alpha-2-HS-glycoprotein was developed. Reliable differentiation of preeclampsia from chronic or gestation hypertension and from normotensive cases was demonstrated with $88 \%$ sensitivity and $96.8 \%$ specificity (AUC $=0.947$ ). Overall, the obtained results confirm the high diagnostic potential of urinary peptidome profiling and can serve as the basis for further creation of new reliable methods for clinical diagnostics of preeclampsia.

Supplementary Materials: The following are available online at http://www.mdpi.com/2075-4418/10/12/1039/s1, Table S1: PEAKS data, the peptides identified in 127 analyzed samples, Table S2: PEAKS data for substantialy represented peptides, Table S3: MaxQuant data for peptides identified in 127 analyzed samples, Table S4: MaxQuant data for substantialy represented peptides, Table S5: PEAKS data for 116 peptide groups, Table S6: Mann-Whitney U-test for 62 substantially represented peptide groups using PEAKS data, Table S7: 570 peptides represented in >15 samples, Table S8: Results of PLS clustering on 570 peptides, Table S9: Dynamic changes of peptide profile in 3 samples from the same patient.

Author Contributions: For research articles with several authors, a short paragraph specifying their individual contributions must be provided.Conceptualization, G.T.S. and E.N.N.; methodology, A.S.K., N.V.Z., V.A.S., A.E.B., M.I.I., N.L.S., W.S. and P.P.; software, V.A.S., M.I.I., W.S. and P.P.; investigation, A.S.K., N.V.Z., V.A.S., A.E.B., M.I.I., N.L.S., K.T.M. and I.P.; resources, K.T.M., I.A.P., Z.S.K., R.G.S. and V.E.F.; writing-original draft preparation, A.S.K., N.V.Z., V.A.S. and N.L.S.; writing—review and editing, A.E.B., M.I.I., I.A.P. and E.N.N.; supervision, A.E.B., Z.S.K., R.G.S. and V.E.F.; project administration, A.S.K. and N.L.S.; funding acquisition, I.A.P. All authors have read and agreed to the published version of the manuscript.

Funding: The research was supported by the Ministry of Science and Higher Education of the Russian Federation (agreement \# 075-00337-20-02, project \# 0714-2020-0006).

Acknowledgments: Authors wish to thank anonymous reviewers for their essential remarks, the Shared Research Facilities of N.N. Semenov Federal Research Center for Chemical Physics RAS and the Core Facility "New Materials and Technologies" of the Emanuel Institute of Biochemical Physics of the Russian Academy of Sciences for providing equipment for sample analysis, and the Laboratory for the collection and storage of biological material (Biobank) at V.I. Kulakov National Medical Research Center for Obstetrics, Gynecology and Perinatology for providing urine samples.

Conflicts of Interest: The authors declare no conflict of interest.

\section{References}

1. Say, L.; Chou, D.; Gemmill, A.; Tuncalp, O.; Moller, A.B.; Daniels, J.; Gulmezoglu, A.M.; Temmerman, M.; Alkema, L. Global causes of maternal death: A WHO systematic analysis. Lancet. Glob. Health 2014, 2 , e323-e333. [CrossRef]

2. Fortunato, S.J.; Menon, R. Distinct molecular events suggest different pathways for preterm labor an premature rupture of membranes. Am. J. Obstet. Gynecol. 2001, 184, 1399-1405. [CrossRef]

3. Bellamy, L.; Casas, J.P.; Hingorani, A.D.; Williams, D.J. Pre-eclampsia and risk of cardiovascular disease and cancer in later life: Systrmatic review and meta-analysis. BMJ 2007, 335, 974. [CrossRef]

4. Backes, C.H.; Markham, K.; Moorehead, P.; Cordero, L.; Nankervis, C.A.; Giannone, P.J. Maternal preeclampsia and neonatal outcomes. J. Pregnancy 2011, 2011, 214365. [CrossRef]

5. Brennan, L.J.; Morton, J.S.; Davidge, S.T. Vascular dysfunction in preeclampsia. Microcirculation 2014, 21, 4-14. [CrossRef] 
6. Buhimschi, I.A.; Nayeri, U.A.; Zhao, G.; Shook, L.L.; Pensalfini, A.; Funai, E.F.; Bernstein, I.M.; Glabe, C.G.; Buhimschi, C.S. Protein misfolding, congophilia, oligomerization, and defective amyloid processing in preeclampsia. Sci. Transl. Med. 2014, 6, 245ra92. [CrossRef]

7. McCarthy, F.P.; Adetoba, A.; Gill, C.; Bramham, K.; Bertolaccini, M.; Burton, G.J.; Girardi, G.; Seed, P.T.; Poston, L.; Chappell, L.C. Urinary congophilia in women with hypertensive disorders of pregnancy and preexisting proteinuria or hypertension. Am. J. Obstet. Gynecol. 2016, 215, 464-e1. [CrossRef]

8. Nagarajappa, C.; Rangappa, S.S.; Suryanarayana, R.; Balakrishna, S. Urinary congophilia in preeclampsia: Experience from a rural tertiary-care hospital in India. Pregnancy Hypertens. 2018, 13, 83-86. [CrossRef]

9. Roberts, J.M.; Hubel, C.A. Oxidative stress in preeclampsia. Am. J. Obstet. Gynecol. 2004, 190, 1177-1178. [CrossRef]

10. Borzychowski, A.M.; Sargent, I.L.; Redman, C.W. Inflammation and pre-eclampsia. Semin. Fetal Neonatal Med. 2006, 11, 309-316. [CrossRef]

11. English, F.A.; Kenny, L.C.; McCarthy, F.P. Risk factors and effective management of preeclampsia. Integr. Blood Press. Control 2015, 8, 7-12. [CrossRef]

12. Redman, C.W.; Sargent, I.L.; Staff, A.C. IFPA Senior Award Lecture: Making sense of pre-eclampsia-two placental causes of preeclampsia? Placenta 2014, 35, S20-S25. [CrossRef]

13. Valdes, G.; Kaufmann, P.; Corthorn, J.; Erices, R.; Brosnihan, K.B.; Joyner-Grantham, J. Vasodilator factors in the systemic and local adaptations to pregnancy. Reprod. Biol Endocrinol. 2009, 7, 79. [CrossRef]

14. Tanbe, A.F.; Khalil, R.A. Circulating and vascular bioactive factors during hypertension in pregnancy. Curr. Bioact. Compd. 2010, 6, 60-75. [CrossRef]

15. Chen, J.; Khalil, R.A. Matrix matelloproteinases in normal pregnancy and preeclampsia. Prog. Mol. Biol. Transl. Sci. 2017, 148, 87-165. [CrossRef]

16. Chelbi, S.T.; Vaiman, D. Genetic and epigenetic factors contribute to the onset of preeclampsia. Mol. Cell. Endocrinol. 2008, 282, 120-129. [CrossRef]

17. Duckitt, K.; Harrington, D. Risk factors for pre-eclampsia at antenatal booking: Systematic review of controlled studies. BMJ 2005, 330, 565. [CrossRef]

18. Rosenberg, T.J.; Garbers, S.; Lipkind, H.; Chiasson, M.A. Maternal obesity and diabetes as risk factors for adverse pregnancy outcomes: Differences among 4 racial/ethnic groups. Am. J. Public. Health 2005, 95, 1545-1551. [CrossRef]

19. Nakajima, T.; Jorde, L.B.; Ishigami, T.; Umemura, S.; Emi, M.; Lalouel, J.M.; Inoue, I. Nucleotide diversity and haplotype structure of the human angiotensinogen gene in two populations. Am. J. Hum. Genet. 2002, 70, 108-123. [CrossRef]

20. Ward, K.; Taylor, R.N. Genetic factors in the etiology of preeclampsia/eclampsia. In Chesley's Hypertensive Disorders in Pregnancy, 4th ed.; Academic Press: Cambridge, MA, USA, 2015; Chapter 4; pp. 57-80. ISBN 978-0-12-407866-6. [CrossRef]

21. Van Dijk, M.; Oudejans, C.B. STOX1: Key player in trophoblast dysfunction underlying early onset preeclampsia with growth retardation. J. Pregnancy 2011, 2011, 521826. [CrossRef]

22. Chen, H.; Zhang, Y.; Dai, L.; Song, Y.; Wang, Y.; Zhou, B.; Zhou, R. Association between polymorphishs in CXCR2 gene and preeclampsia. Mol. Genet. Genomic. Med. 2019, 2019, e578. [CrossRef]

23. Papazoglou, D.; Galazios, G.; Koukourakis, M.I.; Kontomanolis, E.N.; Maltezos, E. Association of -634G/C and 936C/T polymorphisms of the vascular endothelial growth factor with spontaneous preterm delivery. Acta Obstet. Gynecol. Scand. 2004, 83, 461-465. [PubMed]

24. Alrahmani, L.; Willrich, M.A.V. The complement alternative pathway and preeclampsia. Curr. Hypertens. Rep. 2018, 20, 40. [CrossRef] [PubMed]

25. Shimonovitz, S.; Hurwitz, A.; Dushnik, M.; Anteby, E.; Geva-Eldar, T.; Yagel, S. Developmental regulation of the expression of 72 and $92 \mathrm{kd}$ type IV collagenases in human trophoblasts: A possible mechanism for control of trophoblast invasion. Am. J. Obstet. Gynecol. 1994, 171, 832-838. [CrossRef]

26. Isaka, K.; Usuda, S.; Ito, H.; Sagawa, Y.; Nakamura, H.; Nishi, H.; Suzuki, Y.; Li, Y.F.; Takayama, M. Expression and activity of matrix metalloproteinase 2 and 9 in human trophoblasts. Placenta 2003, 24, 53-64. [CrossRef]

27. Su, M.T.; Tsai, P.Y.; Tsai, H.L.; Chen, Y.C.; Kuo, P.L. miR-346 and miR-582-3p-regulated EG-VEGF expression and trophoblast invasion via matrix metalloproteinases 2 and 9. Biofactors 2017, 43, 210-219. [CrossRef] 
28. Montagnana, M.; Lippi, G.; Albiero, A.; Scevarolli, S.; Salvagno, G.L.; Franchi, M.; Guidi, G.C. Evaluation of metalloproteinases 2 and 9 and their inhibitors in physiologic and pre-eclamptic pregnancy. J. Clin. Lab. Anal. 2009, 23, 88-92. [CrossRef]

29. Eleuterio, N.M.; Palei, A.C.; Rangel Machado, J.S.; Tanus-Santos, J.E.; Cavalli, R.C.; Sandrim, V.C. Positive correlations between circulating adiponectin and MMP2 in preeclampsia pregnant. Pregnancy Hypertens. 2015, 5, 205-208. [CrossRef]

30. Chappell, L.C.; Duckworth, S.; Seed, P.T.; Griffin, M.; Myers, J.; Mackillop, L.; Simpson, N.; Waugh, J.; Anumba, D.; Kenny, L.C.; et al. Diagnostic accuracy of placental growth factor in women with suspected preeclampsia: A prospective multicenter study. Circulation 2013, 128, 2121-2131. [CrossRef]

31. March, M.I.; Geahchan, C.; Wenger, J.; Raghuraman, N.; Berg, A.; Haddow, H.; McKeon, B.A.; Narcisse, R.; David, J.L.; Scott, J.; et al. Circulating Angiogenic Factors and the Risk of Adverse Outcomes among Haitian Women with Preeclampsia. PLoS ONE 2015, 10, e0126815. [CrossRef]

32. Maynard, S.E.; Min, J.Y.; Merchan, J.; Lim, K.H.; Li, J.; Mondal, S.; Libermann, T.A.; Morgan, J.P.; Sellke, F.W.; Stillman, I.E.; et al. Excess placental soluble fms-like tyrosine kinase 1 (sFlt1) may contribute to endothelial dysfunction, hypertension, and proteinuria in preeclampsia. J. Clin. Investig. 2003, 111, 649-658. [CrossRef] [PubMed]

33. Bian, Z.; Shixia, C.; Duan, T. First-Trimester Maternal Serum Levels of sFLT1, PGF and ADMA Predict Preeclampsia. PLoS ONE 2015, 10, e0124684. [CrossRef] [PubMed]

34. Venkatesha, S.; Toporsian, M.; Lam, C.; Hanai, J.; Mammoto, T.; Kim, Y.M.; Bdolah, Y.; Lim, K.H.; Yuan, H.T.; Libermann, T.A.; et al. Soluble endoglin contributes to the pathogenesis of preeclampsia. Nat. Med. 2006, 12, 642-649. [CrossRef] [PubMed]

35. Levine, R.J.; Lam, C.; Qian, C.; Yu, K.F.; Maynard, S.E.; Sachs, B.P.; Sibai, B.M.; Epstein, F.H.; Romero, R.; Thandhani, R.; et al. Soluble endoglin and other circulating antiangiogenic factors in preeclampsia. N. Engl. J. Med. 2006, 355, 992-1005. [CrossRef]

36. Ali, S.M.; Khalil, R.A. Genetic, immune and vasoactive factors in the vascular dysfunction associated with hypertension in pregnancy. Expert Opin. Ther. Targets 2015, 19, 1495-1515. [CrossRef]

37. Shah, D.A.; Khalil, R.A. Bioactive factors in uteroplacental and systemic circulation link placental ischemia to generalized vascular dysfunction in hypertensive pregnancy and preeclampsia. Biochem. Pharmacol. 2015, 95, 211-226. [CrossRef]

38. Chafetz, I.; Kuhnreich, I.; Sammar, M.; Tol, Y.; Gibor, Y.; Meiri, H.; Cuckle, H.; Wolf, M. First-trimester placental protein 13 screening for preeclampsia and intrauterine growth restriction. Am. J. Obstet. Gynecol. 2007, 197, e1-e35. [CrossRef]

39. Spencer, C.A.; Allen, V.M.; Flowerdew, G.; Dooley, K.; Dodds, L. Low levels of maternal serum PAPP-A in early pregnancy and the risk of adverse outcomes. Prenat. Diagn. 2008, 28, 1029-1036. [CrossRef]

40. Karumanchi, S.A. Biomarkers in preeclampsia. In Biomarkers of Kidney Disease, 2nd ed.; Academic Press: Cambridge, MA, USA, 2017; pp. 555-594, Chapter 14. [CrossRef]

41. Guo, H.-X.; Zhu, Y.-B.; Wu, C.-P.; Zhong, M.; Hu, S.-W. Potential urine biomarkers for gestational hypertension and preeclampsia. Mol. Med. Rep. 2019, 19, 2463-2470. [CrossRef]

42. Buhimschi, I.A.; Zhao, G.; Funai, E.F.; Harris, N.; Sasson, I.E.; Bernstein, I.M.; Saade, G.R.; Buhimschi, C.S. Proteomic profiling of urine identifies specific fragments of SERPINA1 and albumin as biomarkers of preeclampsia. Am. J. Obstet. Gynecol. 2008, 199, 551-e1. [CrossRef]

43. Chen, G.; Zhang, Y.; Jin, X.; Zhang, L.; Zhou, Y.; Niu, J.; Chen, J.; Gu, Y. Urinary proteomics analysis for renal injury in hypertensive disorders of pregnancy with iTRAQ labeling and LC-MS/MS. Proteom. Clin. Appl. 2011, 5, 300-310. [CrossRef] [PubMed]

44. Carty, D.M.; Siwy, J.; Brennand, J.E.; Zurbig, P.; Mullen, W.; Franke, J.; McCulloch, J.W.; Noth, R.A.; Chappell, L.C.; Mischak, H.; et al. Urinary proteomics for prediction of preeclampsia. Hypertension 2011, 57, 561-569. [CrossRef] [PubMed]

45. Kononikhin, A.S.; Starodubtseva, N.L.; Bugrova, A.E.; Shirokova, V.A.; Chagovets, V.V.; Indeykina, M.I.; Popov, I.A.; Kostyukevich, Y.I.; Vavina, O.V.; Muminova, K.T.; et al. An untargeted approach for the analysis of the urine peptidome of women with preeclampsia. J. Proteom. 2016, 149, 38-43. [CrossRef] [PubMed]

46. Lee, S.M.; Park, J.S.; Norwitz, E.R.; Kim, S.M.; Kim, B.J.; Park, C.-W.; Jun, J.K.; Syn, H.C. Characterization of discriminatory urinary proteomic biomarkers for severe preeclampsia using SELDI-TOF mass spectrometry. J. Perinat. Med. 2011, 39, 391-396. [CrossRef] 
47. Kolialexi, A.; Mavreli, D.; Tounta, G.; Mavrou, A.; Papantoniou, N. Urine proteomic studies in preeclampsia. Proteom. Clin. Appl. 2015, 9, 501-506. [CrossRef]

48. Levine, R.J.; Thadhani, R.; Qian, C.; Lam, C.; Lim, K.-H.; Yu, K.F.; Blink, A.L.; Sachs, B.P.; Epstein, F.H.; Sibai, B.M.; et al. Urinary placental growth factor and risk of preeclampsia. JAMA 2005, 293, 77-85. [CrossRef]

49. Kononikhin, A.S.; Sergeeva, V.A.; Bugrova, A.E.; Indeykina, M.I.; Starodubtseva, N.L.; Chagovets, V.V.; Popov, I.A.; Frankevich, V.E.; Pedrioli, P.; Sukhikh, G.T.; et al. Methodology for Urine Peptidome Analysis Based on Nano-HPLC Coupled to Fourier Transform Ion Cyclotron Resonance Mass Spectrometry. Methods Mol. Biol. 2018, 1719, 311-318. [CrossRef]

50. Babicki, S.; Arndt, D.; Marcu, A.; Liang, Y.; Grant, J.R.; Maciejewsky, A.; Wishart, D.S. Heatmapper: Web-enabled heat mapping for all. Nucleic Acids Res. 2016, 44, W147-W153. [CrossRef]

51. Thevenot, E.A.; Roux, A.; Xu, Y.; Ezan, E.; Junot, C. Analysis of the Human Adult Urinary Metabolome Variations with Age, Body Mass Index, and Gender by Implementing a Comprehensive Workflow for Univariate and OPLS Statistical Analyses. J. Prot. Res. 2015, 14, 3322-3335. [CrossRef]

52. Sergeeva, V.A.; Zakharova, N.V.; Bugrova, A.E.; Starodubtseva, N.L.; Indeykina, M.I.; Kononikhin, A.S.; Frankevich, V.E.; Nikolaev, E.N. The high-resolution mass spectrometry study of the protein composition of amyloid-like urine aggregates associated with preeclampsia. Eur. J. Mass. Spectrom. 2020, 26, 158-161. [CrossRef]

53. Starodubtseva, N.; Nizyaeva, N.; Baev, O.; Bugrova, A.; Gapaeva, M.; Muminova, K.; Kononikhin, A.; Frankevich, V.; Nikolaev, E.; Sukhikh, G. SERPINA1 peptides in urine as a potential marker of preeclampsia severity. Int. J. Mol. Sci. 2020, 21, 914. [CrossRef] [PubMed]

54. De Santa, F.; Totaro, M.G.; Prosperini, E.; Notarbartolo, S.; Testa, G.; Natoli, G. The histone H3 lysine-27 demethylase Jmjd3 links inflammation to inhibition of polycomb-mediated gene silencing. Cell 2007, 130, 1083-1094. [CrossRef] [PubMed]

Publisher's Note: MDPI stays neutral with regard to jurisdictional claims in published maps and institutional affiliations.

(C) 2020 by the authors. Licensee MDPI, Basel, Switzerland. This article is an open access article distributed under the terms and conditions of the Creative Commons Attribution (CC BY) license (http://creativecommons.org/licenses/by/4.0/). 